\title{
COMPARISON BETWEEN CLASS II DIVISION 1 AND 2 MALOCCLUSIONS AND NORMAL OCCLUSION REGARDING TOOTH SIZE DISCREPANCY AND ARCH DIMENSIONS USING DIGITAL MODELS
}

\author{
Marwa Sameh Shamaa*
}

\begin{abstract}
The orthodontists grant a considerable importance to dental arch dimensions to attain more stability of the dentition and better esthetics. The aim of this study was to measure tooth size disharmony and dental arch dimensions in both divisions of class II malocclusion and compare them to Normal occlusion as a control group using three dimensional digital models obtained from 3Shape E1 laser scanner (3Shape, Copenhagen, Denmark). This work was performed on 120 dental casts randomly selected from the records of patients (age range 16- 22 years) attending the Department of Orthodontics, Faculty of Dentistry, Mansoura University. Various parameters were measured including anterior and overall Bolton ratios, maxillary and mandibular intercanine, interfirst premolar and intermolar widths, maxillary and mandibular arch depth, palatal depth, depth of curve of Spee, overjet and overbite. Mean and standard deviation were calculated. Oneway ANOVA was used to detect possible differences between groups. The findings indicate that Class II division 1 malocclusion showed significantly greater maxillary arch depth, palatal depth, mandibular intercanine, interpremolar and intermolar widths and larger overjet amount in comparison with Class II division 2, while revealed significantly higher values of maxillary arch depth, mandibular intermolar width, curve of Spee, overjet and overbite than Normal Class I. On the other hand Class II division 2 malocclusion had significantly greater overall Bolton ratio, maxillary intermolar width, curve of spee depth and overbite than Class II division 1, while it showed deeper curve of Spee and larger amount of overjet and overbite compared to Normal Class I. The results of the current study can help the clinicians in treatment planning and provide guidance for proper selection of arch wires to obtain post-treatment stability.
\end{abstract}

KEY WORDS: Class II malocclusion, tooth size discrepancy, arch dimensions, dental models.

* Lecturer of Orthodontics, Faculty of Dentistry, Mansoura University. 


\section{INTRODUCTION}

Class II is a prevalent type of malocclusion which reveals a considerable anteroposterior maxillary and mandibular arches discrepancy, that might have a skeletal component besides or not. It is further classified into two divisions. Among them, the class II division 2 malocclusion is less popular with limited data available in the literature. ${ }^{1}$

Tooth size discrepancy (TSD) is a disharmony between the individual teeth sizes that presents in different types of malocclusions. The lack of TSD is considered the seventh key for ideal occlusion because significant discrepancies prevent production of optimum results at the termination of orthodontic treatment. ${ }^{2}$ Tooth size and arch size should be in harmony with each other for proper teeth alignment. ${ }^{3}$

Researchers have always drawn attention to information concerning the maxillary and mandibular arch dimensions in human populations. Orthodontic therapy often entails alterations in dental arch dimensions for treatment of the existing malocclusion. Arch dimensions are altered as well by the numerous arch wires utilized throughout the treatment period, influencing the stability of the obtained results. ${ }^{4}$ The size and shape of the dental arches play a substantial role in diagnosis and treatment planning in orthodontics, having an impact on the dental esthetics, available space and the dentition stability. It was found that there is variation in arch dimensions between different classes of Angle's malocclusion. ${ }^{5}$

Assessment of the maxillary and mandibular arch dimensions and their occlusal relations can be carried out on cast models with acceptable reliability. They also permit measurement of the mesiodistal tooth width. ${ }^{6}$ However, the disadvantage of cast models is that they necessitate suitable storage area in addition to the likelihood of fracture which can result in permanent loss of patients' records. Other drawbacks include the inability to send the information anywhere in the world for consultation and the possibility of bacterial accumulation on the models during long term storage ${ }^{7}$. In the modern era, the orthodontic industry announced that the digital study models would be a recent totally digital form of documentation. Analysis of the digital models is done by specific software and the results are displayed immediately on the computer screen with greater accuracy. ${ }^{8}$ With the development of this recent technology for obtaining digital models, the purpose of this work was to compare the TSD and dental arch dimensions in class II division 1 with class II division 2 malocclusion using three dimensional digital models obtained from 3Shape E1 scanner and comparing both divisions to normal Class I occlusion.

\section{MATERIAL AND METHODS}

The study was performed on 120 dental casts of subjects ranging in age from 16- 22 years. A sample of 40 Class II division 1 study models and another sample of 40 Class II Division 2 study models were selected randomly from the records of patients that were treated in the Department of Orthodontics, Faculty of Dentistry, Mansoura University. They were selected according to the following inclusion criteria: (1) bilateral Class II molar relationship in centric occlusion, (2) all permanent teeth present regardless the third molars, (3) no traverse discrepancies like crossbite, (4) no previous orthodontic treatment, (5) no history of trauma, (6) no medical history. A sample of 40 study models of Class I normal occlusion (Control group) was collected from patients' relatives and dental students in the Faculty of Dentistry, Mansoura University. The following inclusion criteria were used to select this sample: (1) bilateral Class I molar relationship in centric occlusion, (2) well aligned teeth with less than $3 \mathrm{~mm}$ of spacing or crowding, (3) all permanent teeth regardless the third molars, (4) no traverse discrepancies like crossbite, (5) no previous orthodontic treatment, (6) no history of trauma, (7) no medical history. 
The sample size of 120 study models (40 models/ group) was selected to give $97 \%$ power in the results of this study (effect size $=.39, \alpha=.05$ ) based on the findings of a previous study ${ }^{9}$ in which the authors found a significant difference in the intercanine width between classes using a similar study design.

The 3Shape E1 equipment was utilized to scan the models. The assessed measurements were as follows:

1. Anterior and overall tooth size ratios according to Bolton ${ }^{10}$ : they were automatically calculated after measuring the mesiodistal diameter of all teeth, except the $2^{\text {nd }}$ and $3^{\text {rd }}$ molars (figure 1 ).

2. Maxillary and mandibular intercanine width ${ }^{11}$ : the distance between the cusp tips of the right and left canines (figure 2).

3. Maxillary and mandibular interfirst premolar width ${ }^{11}$ : the distance between the central sulcus of the right and left $1^{\text {st }}$ premolars (figure 2).

4. Maxillary and mandibular intermolar width ${ }^{11}$ : the distance between the central sulcus of the right and left $1^{\text {st }}$ molars (figure 2 ).

5. Maxillary and mandibular arch depth ${ }^{12}$ : the perpendicular distance between the line joining the mesial surfaces of the $1^{\text {st }}$ molars and the tangent to the labial surfaces of the incisors (figure 3 ).

6. Palatal depth ${ }^{10}$ : it was measured from a line contacting the occlusal plane up to the greatest palatal depth (figure 4).

7. Depth of curve of spee ${ }^{13}$ : the perpendicular distance between a flat plane which was placed on the top of the lower cast (contacting the incisal edges of the centrals and the distal cusp tips of the most posterior teeth in the lower arch) and the deepest buccal tip.

8. Overjet ${ }^{14}$ : it was measured parallel to the occlusal plane from the incisal edge of the most labial upper central incisor to the most labial lower one (figure 5).

9. Overbite ${ }^{14}$ : the vertical overlap of maxillary to mandibular central incisors.

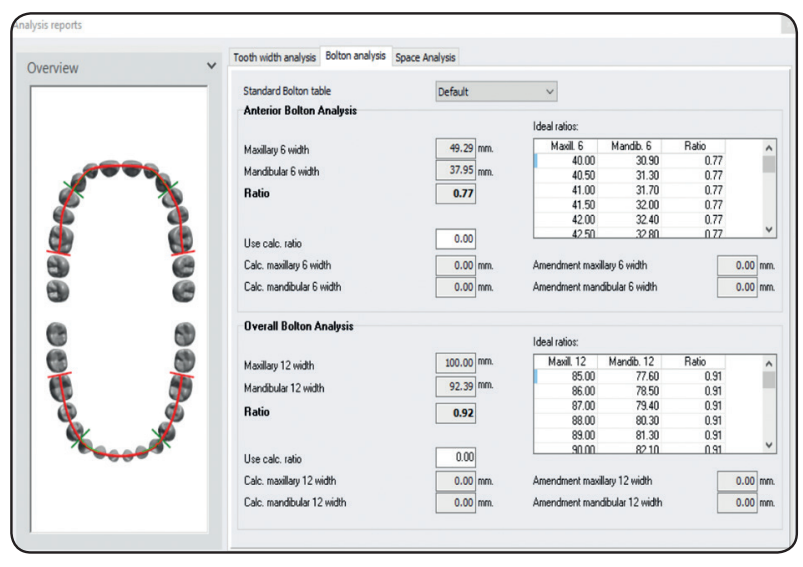

Fig. (1): Bolton analysis

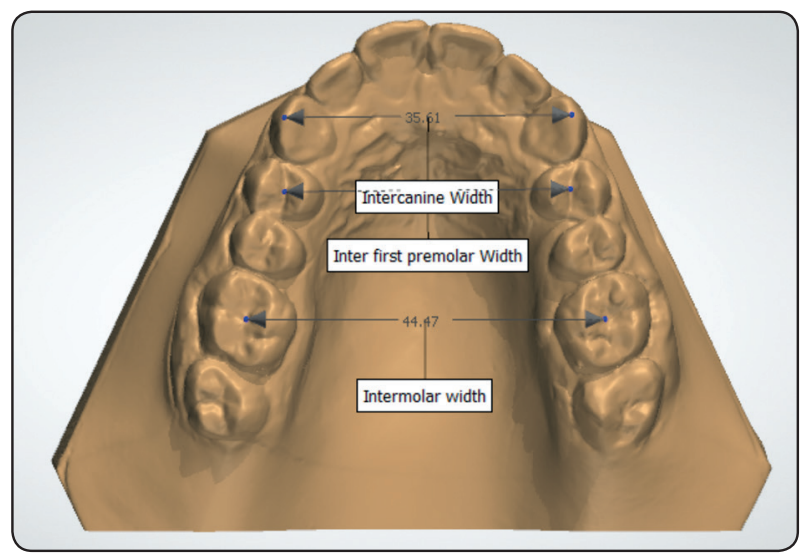

Fig. (2): Arch width measurements

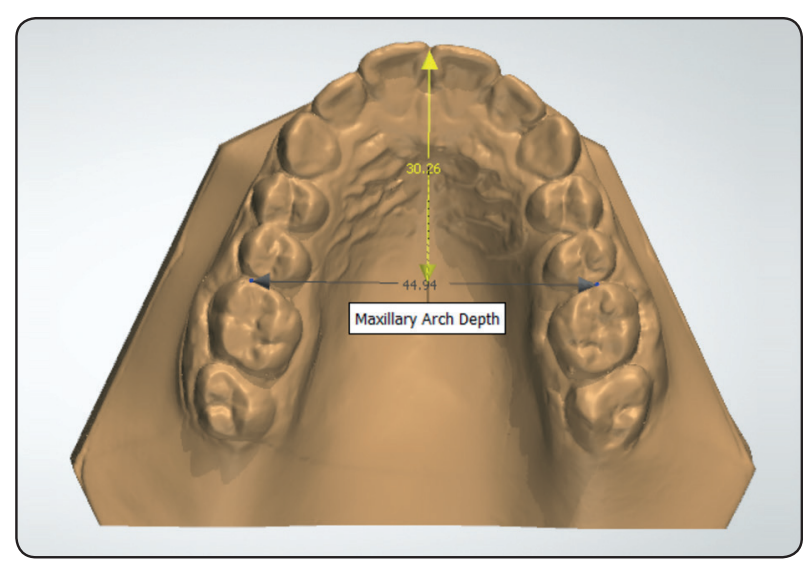

Fig. (3): Arch depth measurement 


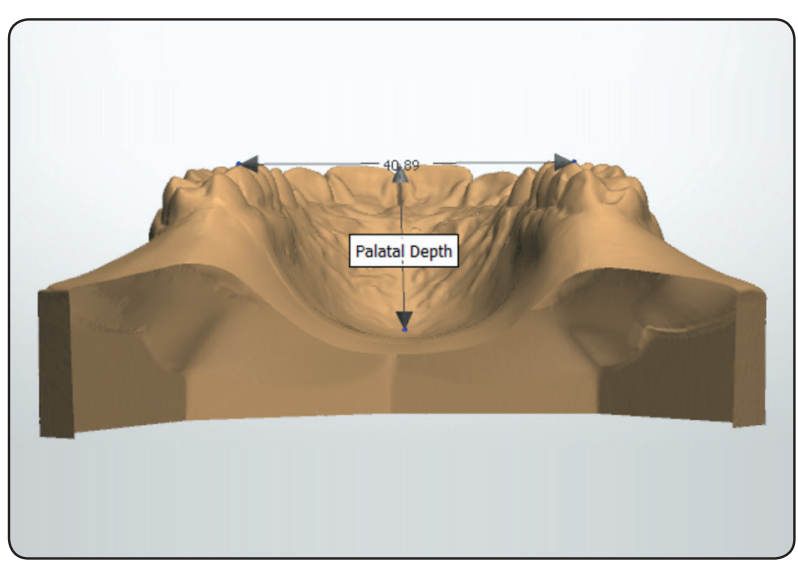

Fig. (4): Palatal depth measurement

The measurements were accomplished after transforming study models into three-dimensional digital models by the 3Shape E1 scanner (3Shape $\mathrm{A} / \mathrm{S}$, Copenhagen, Denmark) and they were analyzed utilizing the 3Shape Ortho Analyzer software (3Shape A/S).

To verify measurement precision, thirty pairs of study casts were randomly selected from the malocclusion groups four weeks later and measured again by the same examiner. Intraclass correlation coefficient was found greater than $80 \%$ which indicates that the data were reliable.

\section{Statistical analysis}

The SPSS statistical package for social science version 22 (SPSS Inc., Chicago, IL, USA) was used for data analysis. The data were parametric and normally distributed. One-way ANOVA was used to detect possible differences between groups followed by multiple comparisons (post hoc test) between each 2 groups using the Bonferroni correction if significant differences were noted. $\mathrm{P}$ is significant if $<0.05$ at confidence interval $95 \%$.

\section{RESULTS}

Comparison of anterior and overall Bolton analysis ratios between groups is presented in table 1. There was no significant difference in the anterior

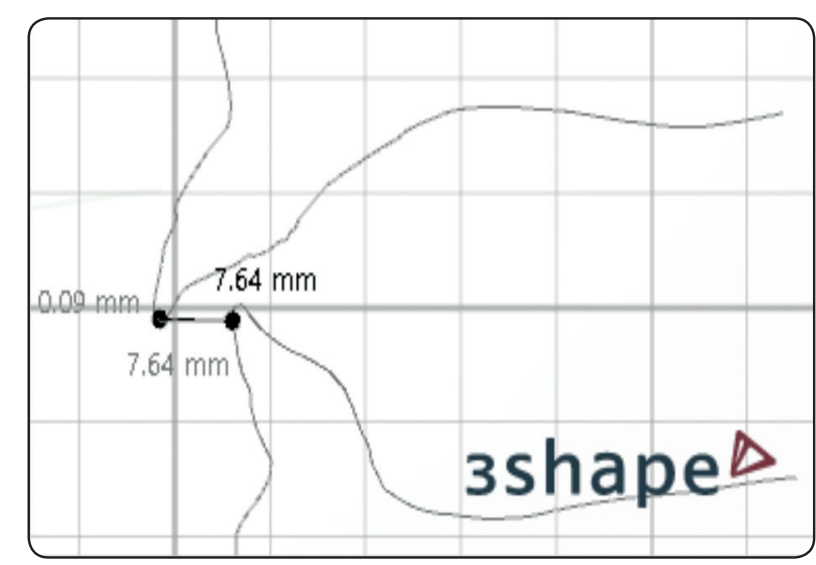

Fig. (5): Overjet measurement

Bolton analysis ratio between groups. However, Class II division 2 and Normal Class I showed significant higher overall ratio than Class II division 1 ( $\mathrm{p}<.002)$. No significant difference was detected between Class II divisions 2 and Class I overall ratios.

TABLE (1): Comparison of anterior and over all Bolton analysis ratios between groups

\begin{tabular}{|c|c|c|c|}
\hline \multicolumn{2}{|c|}{} & $\begin{array}{c}\text { Ant Bolton } \\
\text { analysis ratio }\end{array}$ & $\begin{array}{c}\text { Over all Bolton } \\
\text { analysis ratio }\end{array}$ \\
\hline \multirow{2}{*}{ Normal CL I } & $\mathrm{X}$ & .78 & $1.05 \mathrm{~A}$ \\
\cline { 2 - 4 } & $\mathrm{SD}$ & .03 & .02 \\
\hline \multirow{2}{*}{ CL II Div 1 } & $\mathrm{X}$ & .78 & $1.00 \mathrm{~B}$ \\
\cline { 2 - 4 } & $\mathrm{SD}$ & .04 & .11 \\
\hline \multirow{2}{*}{ CL II Div 2 } & $\mathrm{X}$ & .79 & $1.05 \mathrm{~A}$ \\
\cline { 2 - 4 } & $\mathrm{SD}$ & .04 & .06 \\
\hline \multirow{2}{*}{$\begin{array}{c}\text { One Way ANOVA } \\
\text { p value }\end{array}$} & & .147 & $.002 *$ \\
\hline
\end{tabular}

$X$; mean, SD; standard deviation, * $p$ is significant at 5\%, different letters in the same column indicate significant difference between groups.

Comparisons of maxillary measurements are demonstrated in table 2. There was no significant difference in the maxillary intercanine width between groups. 
However, maxillary interpremolar width, maxillary intermolar width, maxillary arch depth and Palatal depth showed significant difference between groups $(\mathrm{p}<.001)$. Class II division 1 and Class II division 2 groups had statistically significant smaller maxillary interpremolar width than normal Class I. No significant difference between both divisions was noted.

Class II division 1 showed significantly narrower maxillary intermolar width than Class II division 2 and Class I, without significant difference between Class I and Class II division 2 values.

Maxillary arch depth differed significantly between groups with Class II division 1 displaying the highest value followed by Class I then Class II division 2. Regarding the palatal depth, Class II division 1and Class I revealed significantly higher values than Class II division 2, while no significant difference was detected between Class II division 1 and Class I subjects.
Comparisons of mandibular measurements are presented in table 3 . There was a significant difference in all parameters between groups. Class II division 2 group had significantly narrower mandibular intercanine and interpremolar width than class II division 1 and normal Class I groups (with no difference observed between the latter two groups).

Regarding the mandibular arch depth, no significant difference was noted between Class II division 1 and 2. Both divisions revealed significant smaller mandibular arch depth than normal Class 1. Mandibular intermolar width and curve of Spee differed significantly between groups. Class II division 1 showed the largest mandibular intermolar width, followed by Class I and Class II division 2 showed the least value. Class II division 2 exhibited the deepest curve of Spee, followed by Class II division I and normal Class I subjects had the least depth.

TABLE (2): Comparisons of maxillary intercanine, interpremolar and intermolar widths, maxillary arch depth, and Palatal depth between groups

\begin{tabular}{|c|c|c|c|c|c|c|}
\hline & & MaxIC width & MaxIPM width & MaxIM width & Max arch depth & Palatal depth \\
\hline \multirow{2}{*}{ Normal CL 1 } & $\mathrm{X}$ & 34.92 & $37.74 \mathrm{~A}$ & $47.38 \mathrm{~A}$ & $28.11 \mathrm{~A}$ & $20.65 \mathrm{~A}$ \\
\cline { 2 - 7 } & $\mathrm{SD}$ & 1.87 & 1.82 & 1.23 & 1.53 & 1.18 \\
\hline \multirow{2}{*}{ CL II Div 1 } & $\mathrm{X}$ & 33.96 & $35.39 \mathrm{~B}$ & $44.59 \mathrm{~B}$ & $29.93 \mathrm{~B}$ & $20.12 \mathrm{~A}$ \\
\cline { 2 - 7 } & $\mathrm{SD}$ & 2.17 & 2.91 & 1.41 & 2.10 & 1.97 \\
\hline \multirow{2}{*}{ CL II Div 2 } & $\mathrm{X}$ & 34.64 & $34.49 \mathrm{~B}$ & $46.92 \mathrm{~A}$ & $25.62 \mathrm{C}$ & $17.44 \mathrm{~B}$ \\
\cline { 2 - 7 } & $\mathrm{SD}$ & 2.84 & 2.39 & 1.82 & 3.52 & 1.67 \\
\hline $\begin{array}{c}\text { OneWay ANOVA } \\
\text { p value }\end{array}$ & .171 & $<.001 *$ & $<.001 *$ & $<.001 *$ & $<.001^{*}$ \\
\hline
\end{tabular}

$X$; mean, SD; standard deviation, * p is significant at 5\%, different letters in the same column indicate significant difference between groups. 
TABLE (3): Comparisons of mandibular intercanine, interpremolar and intermolar widths, mandibular arch depth and curve of Spee between groups

\begin{tabular}{|l|l|c|c|c|c|c|}
\hline & & $\begin{array}{c}\text { Mand IC } \\
\text { width }\end{array}$ & $\begin{array}{c}\text { Mand IPM } \\
\text { Width }\end{array}$ & $\begin{array}{c}\text { Mand IM } \\
\text { width }\end{array}$ & $\begin{array}{c}\text { Mand arch } \\
\text { depth }\end{array}$ & $\begin{array}{c}\text { CURVE OF } \\
\text { SPEE }\end{array}$ \\
\hline \multirow{2}{*}{ Normal CL I } & $\mathrm{X}$ & $27.59 \mathrm{~A}$ & $33.64 \mathrm{~A}$ & $41.88 \mathrm{~A}$ & $23.99 \mathrm{~A}$ & $1.57 \mathrm{~A}$ \\
\cline { 2 - 7 } & $\mathrm{SD}$ & 2.14 & 2.23 & 2.10 & 1.84 & .29 \\
\hline \multirow{2}{*}{ CL II Div 1 } & $\mathrm{X}$ & $27.54 \mathrm{~A}$ & $32.73 \mathrm{~A}$ & $43.16 \mathrm{~B}$ & $21.40 \mathrm{~B}$ & $2.73 \mathrm{~B}$ \\
\cline { 2 - 7 } & $\mathrm{SD}$ & 1.54 & 1.80 & 2.04 & 1.79 & .55 \\
\hline \multirow{2}{*}{ CL II Div 2 } & $\mathrm{X}$ & $24.91 \mathrm{~B}$ & $29.21 \mathrm{~B}$ & $39.56 \mathrm{C}$ & $21.93 \mathrm{~B}$ & $4.00 \mathrm{C}$ \\
\cline { 2 - 7 } & $\mathrm{SD}$ & 1.66 & 1.74 & 2.59 & 2.06 & .66 \\
\hline \multirow{2}{*}{$\begin{array}{l}\text { One Way ANOVA } \\
\text { p value }\end{array}$} & & $<.001 *$ & $<.001 *$ & $<.001 *$ & $<.001 *$ & $<.001 *$ \\
\hline
\end{tabular}

$X$; mean, SD; standard deviation, * $p$ is significant at 5\%, different letters in the same column indicate significant difference between groups.

Comparisons of overjet and overbite between groups are demonstrated in table 4 . Overjet and overbite vary significantly among groups. The greatest amount of overjet was observed in Class II division 1, followed by Class II division 2 and Class I had the least overjet amount. Class II division 2 showed the deepest overbite, followed by Class II division 1 and Class I showed the least overbite amount.

TABLE (4): Comparisons of overjet and overbite between groups

\begin{tabular}{|l|c|c|c|}
\hline \multirow{2}{*}{ Normal CL 1 } & & OVER JET & OVER BITE \\
\cline { 2 - 4 } & $\mathrm{SD}$ & $2.20 \mathrm{~A}$ & $2.41 \mathrm{~A}$ \\
\hline \multirow{2}{*}{ CL II Div 1 } & $\mathrm{X}$ & $8.35 \mathrm{~B}$ & $3.35 \mathrm{~B}$ \\
\cline { 2 - 4 } & $\mathrm{SD}$ & 2.01 & .89 \\
\hline CL II Div 2 & $\mathrm{X}$ & $3.30 \mathrm{C}$ & $5.25 \mathrm{C}$ \\
\cline { 2 - 4 } & $\mathrm{SD}$ & 1.25 & 1.86 \\
\hline $\begin{array}{l}\text { One Way } \\
\text { ANOVA p value }\end{array}$ & & $<.001^{*}$ & $<.001^{*}$ \\
\hline
\end{tabular}

$X$; mean, SD; standard deviation, * $p$ is significant at 5\%, different letters in the same column indicate significant difference between groups.

\section{DISCUSSION}

Orthodontic treatment should produce favorable contact points between the adjacent teeth. In order to achieve this, the teeth should be proportional in size. Yet, some tooth size discrepancies are not obvious till the terminal stages of orthodontic treatment. Therefore, several methods of determining tooth size proportions have been developed. The most popular method is that introduced by Bolton. He introduced anterior ratio which is calculated by measuring the summed width of the six mandibular to maxillary anterior teeth. The overall Bolton ratio is calculated by measuring the summed width of all mandibular to maxillary teeth (except the $2^{\text {nd }}$ and $3^{\text {rd }}$ permanent molars). ${ }^{10}$

Furthermore, the dental arch dimensions play a pivotal role in diagnosis and treatment planning in orthodontics. The transverse maxillary and mandibular arch dimensions have a fundamental influence on the patient aesthetics. ${ }^{15}$ The most commonly utilized device for determination of the mesiodistal tooth width and the arch length, width and depth is the boley gauge caliper ${ }^{10}$ However, it is quite difficult to properly read or identify the 
measurements with improper vision or inappropriate angle of view. The advent of digital scanning of dental models has been considered to be a precise and less time consuming technique to perform these measurements in the orthodontic practice with high degree of validity. ${ }^{16}$

Digital model analysis permits a 3D estimation of the upper and lower dental arches and their occlusal relation with the capability to zoom in and rotate the three dimensional images without altering their dimensions. This diagnostic tool facilitates data storage and retrieval and could enhance the treatment planning through sharing the electronic data more easily among professionals. ${ }^{17}$ Bukhari et al ${ }^{18}$ concluded that the virtual models (3shape Ortho system) could be considered an accurate alternative to conventional plaster models in performing space analysis irrespective of crowding severity.

The current work was carried out to compare the Bolton ratio and various measurements in class II division 1 malocclusion with class II division 2 using the digital models obtained from 3Shape E1 laser scanner and comparing both divisions to normal Class 1 occlusion. In our study, there was no significant difference in anterior Bolton ratio between groups. These findings are in consistency with Endo et al $^{19}$, while disagree with Othman SA and Harradine NW ${ }^{20}$ who found that $23.4 \%$ of Class II division 1 group and $16.7 \%$ of Class I group had significant discrepancy in the anterior ratio.

The overall Bolton analysis ratio in our results showed significant difference between groups $(\mathrm{p}<.002)$. Class II division 2 and Normal Class I showed significant higher ratio than Class II division 1. No significant difference was detected between Class II division 2 and Class I overall ratios. These results are in line with those of Fattahi et $\mathrm{al}^{21}$ who reported that the Class I group had significantly greater overall ratio than Class II division I subjects.

In the present study, there was no significant difference in maxillary intercanine width between groups, this result is similar to that of Sayin MO and Turkkahraman $\mathrm{H}^{22}$ who recorded that there was no difference in the maxillary intercanine width between Class II division 1 and Class I subjects.

Class II division 1 and Class II division 2 subjects in our study had statistically significant narrower maxillary interpremolar width than Normal Class1. No significant difference between both divisions was noted. This is in accordance with Uysal et al ${ }^{1}$ who reported that the Class II division 1 sample had statistically significant smaller maxillary interpremolar width compared to the Normal occlusion group.

Sayin MO and Turkkahraman $\mathrm{H}^{22}$ detected that the maxillary intermolar width was narrower in Class II division 1than the normal sample. These reports agree with our study where we found that Class II division 1 showed significantly smaller maxillary intermolar width than Class II division 2 and Class 1, without significant difference between Class 1 and Class II division 2 values.

Maxillary arch depth differed significantly between groups with Class II division 1 displaying the highest value followed by Class I and Class II division 2 showed the lowest value. These findings agree with those of Al-Khateeb SN and Abu Alhaija $\mathrm{ES}^{23}$ who recorded that Class II division 1 group have significantly greater maxillary arch depth than Class II division 2 group and they explained that this is due to the maxillary incisors proclination in Class II division 1 malocclusion.

The palate represents one of the most important anatomic structures because of its position and morphology and it can be affected by orthodontic treatment procedures. $^{24}$ In our study, Class II division 1and Class I revealed significantly greater palatal depth than Class II division 2. No significant difference was detected between Class II division 1and Class I subjects. Bhalla A et $\mathrm{al}^{9}$ showed that Class II division 2 group had shallow palatal depth while the deepest palatal depth was observed in the Class I sample. 
Our findings demonstrated that Class II division 2 group had significantly narrower mandibular intercanine and interpremolar width than Class II division 1 and normal Class I groups (with no difference observed between both latter groups). This is in agreement with Uysal et $\mathrm{al}^{1}$ who reported that Class II division 1had larger lower intercanine and interpremolar width measurements compared to Class II division 2 subjects. However, Uysal et al ${ }^{1}$ stated that Class II division 2 and normal occlusion subjects had similar mandibular interpremolar width. Controversy among studies regarding the arch width measurements could be attributed to various factors such as racial and ethnic differences.

As presented in our data, Class II division 1 showed the largest mandibular intermolar width, followed by Class I, while Class II division 2 showed the least value. Similar results were recorded by Buschang et $\mathrm{al}^{25}$ who found that Class II division 1 patients had larger mandibular intermolar width compared to Class II division 2 cases.

Regarding the mandibular arch depth, no significant difference was noticed between Class II division 1 and 2. Both divisions revealed significant smaller mandibular arch depth than normal Class I. The results of the current study are in line with that of AL Ahmar ZT ${ }^{26}$ who reported that Class II division 2 malocclusion group exhibited smaller mandibular arch depth compared to normal Class I group.

Unfortunately, there is a limited number of studies about the relation between different malocclusions and the depth of curve of Spee despite that leveling of curve of Spee is a daily situation in the orthodontic practise and is important factor in diagnosis. Our findings showed that Class II division 2 exhibited the deepest curve of Spee, followed by Class II division 1 and normal Class 1 subjects had the least depth. This is in accordance with Ahmed I et $\mathrm{al}^{27}$ who reported that Class II division 2 malocclusion has the deepest curve of spee proposing that this is affected by the anteroposterior position of the mandible.

The amount of both overjet and overbite considerably affect the variation in the mandibular curve of Spee. Current findings indicated that overbite and overjet vary significantly among groups. The greatest amount of overjet was observed in Class II division 1, followed by Class II division 2 and Class I had the least overjet amount. Class II division 2 showed the deepest overbite, followed by Class II division 1, while Class 1 showed the least overbite amount. Similarly, Walkow TM and Peck $\mathrm{S}^{28}$ declared that Class II division 2 malocclusion is accompanied by severe deep bite that may restrain the dentoalveolar mandibular development in the sagittal plane.

\section{CONCLUSION}

- The Class II division 1 malocclusion showed significantly greater maxillary arch depth, palatal depth, mandibular intercanine, interpremolar and intermolar widths and larger overjet amount in comparison with Class II division 2.

- The Class II division 2 malocclusion had significantly greater overall Bolton ratio, maxillary intermolar width, curve of spee depth and overbite than Class II division 1.

- Class II division 1 revealed significantly higher values of maxillary arch depth, mandibular intermolar width, curve of Spee, overjet and overbite than Normal Class I, while Class II division 2 showed deeper curve of Spee and larger amount of overjet and overbite compared to Normal Class I.

- The results of the current study can help the clinicians in treatment planning and provide guidance for proper selection of arch wires in accordance with arch dimensions to achieve post-treatment stability which represents one of the substantial goals of orthodontic therapy. 
- 3D digital models obtained from the 3Shape E1 scanner can be considered a faithful alternative to plaster models in performing measurements of the dental arch characteristics.

\section{REFRENCES}

1- Uysal T, Memili B, Usumez S, Sari Z. Dental and alveolar arch widths in normal occlusion, class II division 1 and class II division 2. Angle Orthod. 2005 Nov; 75(6):941-7.

2- Bennett JC, McLaughlin RP. Orthodontic Management of the Dentition with the Pre-adjusted Appliance. St Louis, Mo: Mosby; 2002.

3- Moorrees CF, Reed RB. Biometrics of crowding and spacing of the teeth in the mandible. Am $\mathrm{j}$ phys anthropol. 1954 Mar; 12 (1):77-88.

4- Sampson P, Little RM, Årtun J, Shapiro PA. Long-term changes in arch form after orthodontic treatment and retention. Am J Orthod and Dentofac Orthop. 1995 May $1 ; 107$ (5):518-30.

5- Lee RT. Arch width and form: a review. Am J Orthod Dentofac Orthop. 1999 Mar 1; 115 (3):305-13.

6- Matsui RH, Ortolani CLF, Castilho JCM, Costa C. Analysis for orthodontic models through digitized methods. [In Portuguese.] Rev Inst Ciênc Health 2007: 25: 285-90.

7- De Almeida AM, Lauris RCMC, Peixoto AP, Gribel BF, Janson G and Garib DG. Digital models in orthodontics. [In Portuguese.] Pro-dental Orto 2011: 4: 55-80.

8- Paredes V, Gandia JL, Cibrián R. Digital diagnosis records in orthodontics. An overview. Med Oral Patol Oral Cir Bucal. 2006 Jan 1; 11 (1): E 88-93.

9- Bhalla A, Londhe SM, Kumar P, Datana S, Kadu A. Palatal dimension correlation in malocclusions for mixed Indian population. J Dent Res Rev. 2014 Sep 1; 1 (3):137-42.

10- Bolton WA. Disharmony in tooth size and its relation to the analysis and treatment of malocclusion. Angle Orthod. 1958 Jul; 28 (3):113-30.

11- Louly F, Nouer PR, Janson G, Pinzan A. Dental arch dimensions in the mixed dentition : a study of Brazilian children from 9 to 12 years of age. J Appl Oral Sci. 2011 Apr; 19 (2):169-74.

12- Faruqui S, Fida M, Shaikh A. Comparison of tooth and arch dimensions in dental crowding and spacing. $\mathrm{Pk}$ Orthod J. 2012; 4 (2):48-55.
13- Braun S, Hnat WP, Johnson BE. The curve of Spee revisited. Am J Orthod and Dentofac Orthop. 1996 Aug 1; 110 (2):206-10.

14- Sinclair PM, Little RM. Maturation of untreated normal occlusions. Am J Orthod. 1983 Feb 1; 83(2):114-23.

15- Proffit WR, Fields HW, Larson BE and Sarver DM. Orthodontic treatment planning: from problem list to specific plan. Contemporary orthodontics. $6^{\text {th }} \mathrm{Ed}$. St Louis (Missouri): Mosby Inc; 2019:208-36.

16- Mullen SR, Martin CA, Ngan P, Gladwin M. Accuracy of space analysis with emodels and plaster models. Am J Orthod and Dentofac Orthop. 2007 Sep 1; 132 (3):346-52.

17- Flügge TV, Schlager S, Nelson K, Nahles S, Metzger MC. Precision of intraoral digital dental impressions with iTero and extraoral digitization with the iTero and a model scanner. Am J Orthod and Dentofac Orthop. 2013 Sep 1; 144 (3):471-18.

18- Bukhari SA, Reddy KA, Reddy MR, Shah SH. Evaluation of virtual models (3Shape Ortho System) in assessing accuracy and duration of model analyses based on the severity of crowding. Saudi J Dent Res. 2017 Jan 1; 8 (12):11-8.

19- Endo T, Abe R, Kuroki H, Oka K, Shimooka S. Tooth size discrepancies among different malocclusions in a Japanese orthodontic population. Angle orthod. 2008 Nov; 78 (6):994-9.

20- Othman SA, Harradine NW. Tooth-size discrepancy and Bolton's ratios: a literature review. J orthod. 2006 Mar 1; 33 (1):45-51.

21- Fattahi HR, Pakshir HR, Hedayati Z. Comparison of tooth size discrepancies among different malocclusion groups. Eur J Orthod. 2006 Jun 9; 28 (5):491-5.

22- Sayin MO, Turkkahraman H. Comparison of dental arch and alveolar widths of patients with Class II division 1 malocclusion and subjects with Class I ideal occlusion. Angle Orthod. 2004; 74:356-60.

23- Al-Khateeb SN, Abu Alhaija ES. Tooth size discrepancies and arch parameters among different malocclusions in a Jordanian sample. Angle orthod. 2006 May; 76 (3):459-65.

24- Haas AJ. The treatment of maxillary deficiency by opening the midpalatal suture. Angle Orthod. 1965 Jul; 35 (3):200-17. 
25- Buschang PH, Stroud J, Alexander RG. Differences in dental arch morphology among adult females with untreated Class I and Class II malocclusion. Eur J Orthod. 1994 Feb 1; 16 (1):47-52.

26- AL Ahmar ZT. Three Dimensional Study of Dental Arches Features in Class II, Division 2 Malocclusion Iraqi Patients (A Cross-Sectional Comparative Study). Dentistry.uobabylon.edu.iq. 2011Oct; 1-18.
27- Ahmed I, Nazir R, Ahsan T. Influence of malocclusion on the depth of curve of Spee. JPMA. J Pk Med Assoc. 2011 Nov; 61(11):1056-9.

28- Walkow TM, Peck S. Dental arch width in Class II Division 2 deep-bite malocclusion. Am J Orthod and Dentofac Orthop. 2002 Dec 1; 122 (6):608-13. 